\title{
TROTSKI Y CUBA. \\ POLÍTICA, FICCIÓN E HISTORIA EN LA ERA POS-SOVIÉTICA
}

\author{
POR \\ RAFAEL ROJAS \\ CIDE, México DF
}

Buena parte de la recepción, a favor o en contra, de la novela El hombre que amaba los perros (2009), de Leonardo Padura, ha estado relacionada con el impacto de la narración de una historia políticamente no reconocida e, incluso, silenciada en la esfera pública de la isla por décadas. La residencia de Ramón Mercader, el asesino de León Trotski, en La Habana, hasta su muerte de cáncer en 1978, protegido por el gobierno de Fidel Castro, constituye el núcleo inconfeso de un relato que dota a la ficción de una naturaleza política, en la medida que cuenta algo que la historia oficial del Estado cubano ocultó o manejó con extrema discreción. ${ }^{1}$

El asilo de Mercader en Cuba, durante los años de mayor sovietización del sistema político cubano, es una buena muestra de la intimidad que llegó a establecerse entre La Habana y Moscú tras el respaldo del gobierno de Fidel Castro a la invasión de Checoslovaquia por las tropas del Pacto de Varsovia, en 1968, y, sobre todo, de la integración de la isla al CAME en 1971. Mercader, que era coronel de la KGB y había sido condecorado en la URRS con la máxima Orden Lenin, que se asignaba a los héroes del comunismo, residió los últimos años de su vida en el apacible barrio de Miramar de La Habana, otrora residencia de la burguesía capitalina y, tras la Revolución de 1959, hábitat de las nuevas élites del país. El secretismo con que el gobierno cubano condujo la estancia de Mercader en Cuba estuvo relacionado con la pugna por la rehabilitación de Stalin que tuvo lugar, en los años 60 y 70, en el bloque soviético, tras la caída de Nikita Kruschev en 1965.

La novela de Padura fue una deliberada confrontación de aquel silencio por medio del tejido de tres historias, la de Trotski, la del propio Mercader y la de Iván, un joven

\footnotetext{
La recepción de El hombre que amaba los perros (2009), ha sido más intensa fuera de la isla que dentro, lo cual es bastante revelador de la opacidad de la esfera pública cubana en cuanto a temas relacionados con stalinismo, el trotskismo y la conexión de La Habana con Moscú. Para una muestra de esa recepción, ver Samuel Farber, "En diálogo con El hombre que amaba los perros de Leonardo Padura"; Haroldo Dilla, "De utopías, revoluciones y escombros" 5-8; Alejandro Armengol, "Padura, el Che y la atracción trotskista".
} 
escritor y periodista cubano que en los años 70 conoce al asesino del líder bolchevique en La Habana y, a través de ese contacto y de la documentación que le facilita, puede reconstruir la trama oculta bajo el tabú. Un tabú oficial que, sin embargo, descansaba bajo un consenso sólido en la cúpula del Estado cubano, a favor de la adscripción del dogma marxista-leninista y del modelo de sociedad construido en la Unión Soviética y los países del socialismo real de Europa del Este. Según las élites comunistas de todos esos gobiernos, Trotski había sido un traidor y Mercader, un héroe. Nada más natural que La Habana, única playa tropical de aquel comunismo planetario, fuera el refugio del asesino.

El debate sobre la novela de Padura tiene una importante dosis extraliteraria, aportada, en primer lugar, por el propio escritor. La novela aparece veinte años después de la caída del Muro de Berlín y en medio de la construcción de un capitalismo de Estado en Cuba, que arranca desde los 90, y que intenta borrar el pasado soviético de la isla. Los estudios más recientes sobre las conexiones culturales y políticas entre la Unión Soviética y Cuba han dado cuenta de la profundidad jurídica e ideológica de la inscripción de la isla en el bloque soviético. ${ }^{2}$ Sin embargo, esa pertenencia de Cuba a un campo socialista, fuertemente marcado por el legado stalinista, desdibuja en buena medida la experiencia menos conocida del trotskismo en la isla: una documentación que Padura también elude. En las páginas que siguen intentaré explorar esa paradoja.

\section{Stalinismo y trotskismo en Cuba}

Aunque la opción de una inserción en el campo socialista de Europa del Este y la presencia creciente de nociones básicas del marxismo-leninismo, en la esfera pública de la isla, eran notables desde principios de los años 60, la institucionalización del socialismo cubano más claramente endeudada con el modelo soviético es posterior a 1968. En la historia política de la URSS este año marca, a su vez, el inicio de una restalinización del socialismo soviético, tras la breve experiencia del deshielo. En 1968, como sostiene el estudioso de la historia cultural soviética Boris Kagarlitsky, se reinició una rehabilitación de Stalin en la URSS, a la vez que un ambivalente desplazamiento ideológico en el que coexistían las críticas a las teorías sociales y económicas de Trofim Lysenko, una de las eminencias grises del stalinismo, y la represión contra jóvenes intelectuales críticos como Sinyavsky y Daniel, que fueron arrestados y sometidos a un juicio muy parecido al que sufriría el poeta cubano Heberto Padilla en 1971 (227-30).

2 Cito sólo algunos títulos en una abultada bibliografía reciente sobre el tema: Jacqueline Loss y José Manuel Prieto, eds., Caviar with Rum; Jacqueline Loss, Dreaming in Russian; Odette CasamayorCisneros, Utopia, distopia e ingravidez; Damaris Puñales-Alpízar, Escrito en cirilico; Mabel Cuesta, Cuba postsoviética; Guillermina de Ferrari, Community and Culture in Post-soviet Cuba. 
La institucionalización del socialismo cubano, entre 1971 y 1976, y su proyección sobre la política cultural e ideológica de la isla, que va del Primer Congreso de Educación y Cultura en el 71 a la creación del Ministerio de Cultura en el 76, reforzó una corriente pro-estalinista dentro del comunismo cubano, que se originaba en las filas del viejo Partido Socialista Popular y que en los años 60 se había renovado por medio de una nueva generación de comunistas, formados en las escuelas de cuadros de Moscú y La Habana. Toda la documentación ideológica que acompaña al Primer Congreso del Partido Comunista de Cuba, en 1975, y el propio texto constitucional de 1976, exponen de manera inequívoca la centralidad del modelo soviético, creado por Stalin, dentro de los referentes de la construcción del Estado socialista en Cuba.

El filósofo neomarxista francés, Étienne Balibar, dejó clara aquella identidad stalinista del proyecto soviético en los 70 en su ensayo Sobre la dictadura del proletariado (1977), aparecido al año siguiente del XXII Congreso del Partido Comunista de Francia, que coincidió con la promulgación de la Constitución cubana. Sostenía Balibar que lo que la Unión Soviética recomendaba en aquellos años a los comunistas del mundo, empezando por los occidentales, era un abandono de las tesis leninistas sobre la revolución, el Estado, la lucha de clases y la dictadura proletariado, y una comprensión del tránsito socialista como un periodo supraclasista, en el que las instituciones diseñadas por Stalin cuarenta años antes, en 1936, entraban en una estabilización definitiva (11-29).

Al decretarse que la lucha de clases había sido superada por medio de la integración de todos los sectores sociales en un mismo "pueblo" soviético, compuesto por obreros, campesinos, trabajadores manuales e intelectuales, se rearticulaba una idea de nación excepcional, muy parecida a la burguesa predominante en algunas naciones occidentales. Según Balibar, esa condición se repetía institucional e ideológicamente en todas las llamadas "democracias populares" de Europa del Este. La "dictadura del proletariado" de Lenin y Trotski se había convertido, finalmente, en los años 70, en una dictadura sobre el proletariado, ejercida por una burocracia reconstituida en nueva clase dominante.

Balibar, discípulo de Louis Althusser, citaba centralmente a Marx y a Lenin en su libro, pero era evidente su intento de atraer el leninismo y el trotskismo a una corriente del marxismo occidental, opuesta a la stalinización de la izquierda en la Guerra Fría. Balibar mencionaba a la Revolución cubana en los 60, la descolonización vietnamita y al mayo del 68 como algunos de los últimos momentos de resistencia a esa institucionalización del stalinismo (144). Pero para mediados de los 70, aquel socialismo de Estado también había alcanzado a Cuba. La tesis de que la Unión Soviética y los socialismos reales de Europa del Este eran dictaduras burocráticas había sido sostenida por Trotski y los trotskistas desde los años 30, es decir, desde el momento en que ese modelo de Estado quedó plenamente diseñado en la Constitución de 1936. Aunque no citara a Trotski, los documentos que Balibar sometía a crítica -la Constitución de la URSS de 1936 y los ensayos de Stalin Cuestiones de leninismo (1926) y Sobre el

$111 \frac{\text { Revista Iberoamericana, Vol. LXXXV, Núm. 269, Octubre-Diciembre 2019, }}{1257-1270}$ 
materialismo dialéctico y el materialismo histórico (1938)- eran los mismos que había impugnado el trotskismo por cuatro décadas (21-24).

Desde sus ensayos La revolución traicionada (1936) y Stalin (1940), Trotski había señalado que desde la muerte de Lenin, en 1924, el stalinismo había conducido la Unión Soviética a una "reacción termidórica", que culminaba con la Constitución del 36. Esa Constitución, que fue incluida dentro de las “obras" escritas por Stalin en las ediciones del PCUS o en sus versiones en castellano, como la mexicana de la Editorial Dialéctica de 1937, viviendo ya Trotski en este país, es la más clara plasmación de la continuidad del sistema soviético entre los años 30 y 70. En su libro El mito soviético ante la realidad (1946), Arthur Koestler hizo observaciones muy pertinentes sobre la legislación secundaria, que antecedió y siguió a dicha Constitución, dentro del Código Legislativo Soviético, y que tipificó penalmente la represión de la oposición y la criminalización de la disidencia, además de criminalizar severamente la deserción, la emigración, la homosexualidad, el aborto, la vagancia y, por supuesto, el "liberalismo" (84-94).

El mismo año de la proclamación de la Constitución soviética, Trotski publicó su ensayo La revolución traicionada (1936), la primera y más completa refutación de la Carta Magna stalinista. Sostenía el líder bolchevique que con la institucionalización del nuevo Estado soviético, los ideales de la Revolución de Octubre eran resueltamente abandonados. La introducción de un capitalismo autoritario de Estado, encabezado por una burocracia represiva, se convertía a partir de entonces en un proyecto deliberado, que gozaría del respaldo de las democracias occidentales. La idea del "socialismo en solo país" finalmente había triunfado y sólo cabía esperar lo peor lo de la consolidación del stalinismo. Es interesante releer la manera en que Trotski describía el núcleo totalitario de la Constitución soviética:

La nueva carta "garantiza" a los ciudadanos las así llamadas "libertades" de expresión, de prensa, de reunión, de manifestación callejera. Pero cada una de esas garantías reviste la forma de una sólida mordaza o de grilletes en las manos y en los pies. La libertad de prensa significa la continuación de una censura previa implacable, cuyas cadenas son sujetadas por el Secretariado del Comité Central, a quien nadie ha elegido. La libertad de adulaciones bizantinas está, obviamente, "garantizada" en su totalidad... El crudo e ignorante comando de las ciencias, la literatura y el arte será completamente preservado. La "libertad de reunión" significará, como antiguamente, la obligación de asistir a reuniones convocadas por las autoridades para tomar resoluciones decididas de antemano. (La revolución 217)

Se refería Trotski a los artículos $124^{\circ}$ y $125^{\circ}$ de la Constitución de la URSS, que reconocían las libertades de conciencia, de palabra, de prensa, de reunión y de "desfilar y manifestar en la calle" (Stalin, Constitución 169). Pero a la concesión de esos derechos se imponía un marco institucional único, controlado por el Estado y el

$111 \frac{\text { Revista Iberoamericana, Vol. LXXXV, Núm. 269, Octubre-Diciembre 2019, }}{1257-1270}$ 
Partido Comunista: "la efectividad de estos derechos se garantiza poniendo a disposición de los trabajadores y de sus organizaciones, las imprentas, los almacenes de papel, las calles, las vías de comunicación, postales y eléctricas y otras condiciones materiales necesarias al ejercicio de esos derechos" (Stalin, Constitución 70). Esta concepción restrictiva de las libertades públicas estaba incorporada a un orden social, económico y político que garantizaba el control del Estado y el partido único sobre la propiedad, la sociedad civil y los medios de comunicación.

Cuarenta años después de la promulgación de la Constitución stalinista, el Partido Comunista de Cuba adoptó un texto constitucional que, en sus principios fundamentales de organización de la sociedad y el Estado, reproducía el orden soviético. El partido único, la ideología "marxista-leninista", el "ateísmo científico", la propiedad estatal y el reordenamiento de la sociedad a partir de "organizaciones de masas", es decir, el meollo dogmático y pragmático, doctrinario y normativo de la Constitución cubana de 1976, estaba directamente tomado de la Carta Magna stalinista (Cuesta, Constituciones 450-56). Antes de la Constitución cubana de 1976, todos esos elementos institucionales e ideológicos sólo existían en la Unión Soviética y los socialismos reales de Europa del Este. Ramón Mercader, el asesino de León Trotski, residía en La Habana cuando esa Constitución fue promulgada. Los artículos $124^{\circ}$ y $125^{\circ}$, que criticaba Trotski en la Constitución stalinista de 1936 , se repitieron literalmente en el $52^{\circ}$ y el $53^{\circ}$ de la cubana de 1976, todavía vigentes (Cuesta, Constituciones 463).

La idea de una adaptación cubana de aquel modelo había surgido, como en casi todos los países latinoamericanos, poco después de la promulgación de la ley de leyes soviética, dentro del Partido Comunista de la isla. Blas Roca, uno de sus líderes, había escrito a principios de los 40 el ensayo "Los fundamentos del socialismo en Cuba" (1943), que arrancaba con un exergo de la entrevista de Stalin con el periodista norteamericano Roy Howard, en 1936, en la que el líder soviético explicaba el nuevo orden constitucional y sugería que a ese sistema se podía llegar por vía de una revolución, o no (Los fundamentos 4). En 1943, cuando escribió su libro, los comunistas cubanos, reunidos en el Partido Socialista Popular, formaban parte del primer gobierno de Fulgencio Batista, y por lo tanto pensaban que no era necesaria otra revolución después de la de 1933.

En 1960, Roca reeditó su libro y le agregó un nuevo capítulo sobre "la necesidad histórica de la Revolución de enero del 59", proponiendo que el mismo programa trazado por Stalin en 1936 debía realizarse en el nuevo contexto revolucionario (Los fundamentos 135-52). La tarea consistía en crear un nuevo tejido de "organizaciones económico-sociales", subordinadas al gobierno revolucionario, y un nuevo Partido Comunista, con el fin de ir edificando gradualmente el nuevo Estado socialista (162$64 ; 176-78)$. Ese es el proyecto que, en resumidas cuentas, triunfa entre 1971 y 1976 , luego de medir fuerzas con el guevarismo, el marxismo heterodoxo, el nacionalismo revolucionario no pro-soviético y otras corrientes de izquierda en los 60 .

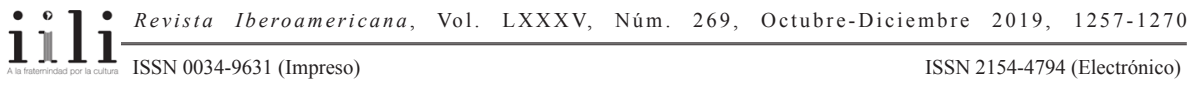


Si existía un stalinismo cubano desde los años 30, ¿qué tanto habían circulado en Cuba, para 1976, las ideas de Trotski y otros críticos del proyecto stalinista desde la izquierda marxista europea o americana? Más de lo que generalmente admite el discurso oficial y sugiere la novela de Padura. Los historiadores Sergio Méndez Moissen, Rafael Soler y Eric Toussaint, han reconstruido la conexión cubana de los trotskistas desde los años 30, documentando la existencia de un movimiento borrado por la historia oficial de la Revolución cubana y del propio partido comunista, antes y después de enero de $1959 .{ }^{3}$ En la correspondencia entre León Trotski y Charles Curtiss, líder de la IV Internacional, en la propia documentación de esta última y en los escritos latinoamericanos de Trotski se menciona con frecuencia el capítulo cubano del trotskismo, del que formaron parte líderes obreros como Sandalio Junco, Gustavo Fraga, Ramón Brea y Pablo Díaz, y asociaciones como La Joven Cuba (Escritos latinoamericanos 122; 215-23).

Carlos Franqui cuenta que hacia 1959, dentro de la joven intelectualidad revolucionaria reunida en torno al magazine Lunes de Revolución, dirigido por Guillermo Cabrera Infante, había un rechazo bastante generalizado al stalinismo y una acusada simpatía por Trotski $(262 ; 318 ; 365 ; 417 ; 450)$. En el tercer número de Lunes de Revolución, que puede ser leído como una declaración de principios ideológicos de aquel suplemento literario, se incluía, junto a pasajes de Los derechos del hombre de Thomas Paine, del Manifiesto comunista de Marx y Engels, y fragmentos de Saint-Just y Piotr Kropotkin, un capítulo de la Historia de la revolución rusa (1932) de Trotski, donde podía advertirse la discordancia entre la teoría de la "revolución permanente" y la doctrina del "socialismo en un solo país" stalinista (Luis 57). El paso de Ramón Mercader por La Habana, en 1960, tras su liberación de la cárcel mexicana de Lecumberri, camino a Checoslovaquia, fue visto por Cabrera Infante, Franqui y otros editores de aquella publicación, con inquietud, como un temprano indicio de la alianza entre La Habana y Moscú.

La simpatía por Trotski se lee en buena parte de la obra periodística de Cabrera Infante. En su respuesta a Primera Plana, en julio de 1968, tras los primeros ataques públicos que le dirigió la burocracia cultural de la isla, Cabrera Infante se colocaba en una tradición de disidentes del stalinismo, en la que distinguía a Trotski, Gide, Koestler, Orwell, Silone, Richard Wright y Milosz (Mea Cuba 480). Luego, Cabrera Infante asoció a Trotski con José Martí - "Martí sería así nuestro Trotski temprano: ideólogo, político, guerrillero fallido pero suicida certero, el felo de se con fe en la tumba abierta"o con Carlos Franqui, borrado como el propio líder bolchevique de las fotos oficiales de la Revolución cubana, o con Calvert Casey, el escritor de origen norteamericano,

Sergio Méndez Moissen, "El trotskismo cubano en la Revolución de 1933"; Eric Toussaint, "Revolucionarios "olvidados de la historia".

$111 \frac{\text { Revista Iberoamericana, Vol. LXXXV, Núm. 269, Octubre-Diciembre 2019, } 1257-1270}{\text { ISSN 2154-4794 (Electrónico) }}$ 
homosexual y amigo de "trotskistas y utopistas cubanos", que acabarían reconociendo el "carácter stalinista del gobierno fidelista", o con el Che Guevara, a quien veía como el mayor partidario de la "revolución permanente" dentro de la dirigencia cubana (Mea Cuba 601; 637; 639; 850; 1044).

A pesar de haber pasado gran parte de su exilio en los momentos álgidos de la Guerra Fría no hay en Cabrera Infante un juicio sobre Trotski que remita al papel del líder bolchevique en la fundación de la Unión Soviética, desde un punto de vista anticomunista. Trotski aparece siempre como víctima de Stalin, en la obra de Cabrera Infante, y como portador de una idea del socialismo más abierta a las libertades públicas y el arte de vanguardia. Su asesinato en México, por órdenes de Stalin y ejecutado por el agente de la NKVD, Ramón Mercader, es para Cabrera Infante un episodio central de la historia del socialismo y la izquierda en el siglo XX, que en buena medida hacía moralmente cuestionable la introducción del stalinismo en la isla a mediados del siglo XX.

El sentido de las parodias de "la muerte de Trotsky referida por varios escritores cubanos, años después -o antes", en Tres tristes tigres (1967), tiene que ver con aquella certeza (Montenegro y Santí 327-52). Cabrera Infante ponía a los mayores escritores de la isla (José Martí, José Lezama Lima, Virgilio Piñera, Lydia Cabrera, Lino Novás Calvo, Alejo Carpentier y Nicolás Guillén) a narrar el asesinato de Trotski por Mercader en Coyoacán, en 1940, con el fin de practicar un ejercicio de estilo, que dejara codificadas o superadas las escrituras de sus antecesores en la gran tradición literaria cubana. Pero también buscaba el autor de Tres tristes tigres, colocar aquel crimen en el centro de la literatura nacional y de su canon estético, en un momento en que la posibilidad de la adopción del modelo stalinista en la isla se hacía cada vez más real.

La versión definitiva de Tres tristes tigres apareció en Seix Barral en 1967, pero había ganado el Premio Biblioteca Breve, de ese editorial, en 1964. Los años de escritura del manuscrito coinciden, por tanto, con el periodo en que la dirigencia cubana se debate entre el marxismo de la Nueva Izquierda, alentado en buena medida por el Che Guevara, y el modelo soviético. Al año siguiente de la publicación de la novela, en 1968, ya las señales de la derrota de la corriente guevarista dentro de la nueva élite del poder en Cuba parecían evidentes a Franqui, Cabrera Infante y otros intelectuales cubanos críticos o disidentes. Una de las últimas aproximaciones públicas al pensamiento trotskista, dentro de la isla, se produciría con la publicación de un ensayo del marxista alemán-belga, líder de la IV Internacional, Ernest Mandel en la revista Pensamiento Crítico (1968-1971) (Martínez Heredia 394-411).

Tras el cierre de Pensamiento Crítico en 1971, el trotskismo fue formalmente incluido dentro de las corrientes "revisionistas" del marxismo, que debían ser combatidas por los aparatos ideológicos del Estado cubano, según el Primer Congreso de Educación y Cultura de aquel año. Varios intelectuales trotskistas latinoamericanos, como el argentino Nahuel Moreno, rompieron entonces con el régimen de la isla y lo incluyeron, como

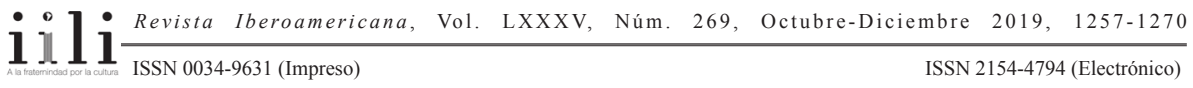


a los socialismos reales de Europa del Este, dentro de las "revoluciones congeladas" del siglo XX, que continuaban la dominación capitalista por medio de una burocracia gobernante (Rojas). En los años 70 Cuba era, en efecto, uno de los lugares más seguros para Ramón Mercader.

\section{El ETHOS DE LA AMBIVALENCIA}

El hombre que amaba los perros (2009) se publicó veinte años después de la caída del Muro Berlín, aunque, según su autor, comenzó a escribirse en 1989, el año en que culminaba el siglo soviético (Padura 571). Su proceso de escritura abarca, pues, las dos décadas del momento pos-soviético de la historia de Cuba y el texto acoge algunos de los dilemas y ambigüedades de ese periodo. Como ficción histórica que recrea las biografías de León Trotski y Ramón Mercader se coloca en una perspectiva similar a la de novelas Soldados de Salamina (2001) de Javier Cercas o El ruido de las cosas al caer (2011) de Juan Gabriel Vásquez, que narran desde un después de la guerra civil, en este caso, un después de la Guerra Fría.

El asesinato de Trotski por Mercader en Coyoacán, diseñado y ordenado por la NKVD y Stalin, es uno de los grandes magnicidios de todos los tiempos, pero también uno de los más célebres antecedentes de la Guerra Fría. Cuando Trotski fue ejecutado, buena parte del pensamiento liberal y socialista de Occidente se movilizaba a su favor, en buena medida, gracias a la intervención de pensadores no marxistas como John Dewey y Bertrand Russell, que lo defendieron de los ataques de Stalin. El apoyo de la izquierda liberal a Trotski en los 40 fue, en buena medida, el punto de partida de la posterior inscripción del trotskismo en el polo intelectual antitotalitario del Congreso para la Libertad de la Cultura y otras instituciones y publicaciones de la Guerra Fría. ${ }^{4}$

Al intentar narrar desde un después, la novela de Padura opera por medio de una "anamnesis" de la pugna entre stalinismo y trotskismo, en un sentido similar al sugerido por el teórico neomarxista Frank Ruda (Ruda 177-218). En el siglo XXI se instalan como "imposibles" esas ideologías rivales de la Guerra Fría, suscitando todo tipo de discursos de la nostalgia y políticas de la memoria. Stalinismo y trotskismo, como modalidades concretas de la idea comunista en el siglo XX, se involucran en la dialéctica de duelo y melancolía que, a decir de Jodi Dean, otra filósofa neomarxista, caracteriza a las estrategias de la memoria en la izquierda, siguiendo ensayos conocidos de Sigmund Freud y Walter Benjamin (Dean 99-115). A cierto nivel de ese "comunismo como deseo", stalinismo y trotskismo entran en un plano de equivalencia perturbador.

4 Sobre la Guerra Fría cultural ver, por ejemplo, Frances Stonor Saunders, La CIA y la Guerra Fría cultural 84, 101, 137, 229, 233; Patrick Iber, Neither Peace nor Freedom 22-23, 28-30 y 36-41. 
La novela de Padura se coloca en esa perspectiva, por momentos, equidistante, ofreciendo al lector la posibilidad de una identificación paralela o alternativa con Ramón Mercader o León Trotski. El hombre que amaba los perros (2009) establece esa diferencia marcada con el trotskismo y el stalinismo cubano previos. Para Calvert Casey o Guillermo Cabrera Infante, a quien cita en un momento Padura, junto a $E l$ profeta exiliado de Issac Deutscher, como una de las fuentes de la investigación de Iván, hubiera resultado inconcebible la humanización del asesino Mercader, que se lee en la novela (Padura 245). Uno de los mayores juegos conceptuales que hay debajo de esta obra es la manipulación simultánea de ambos legados que facilita, a la vez, la identificación o el extrañamiento con uno u otro personaje histórico.

Trotski y Mercader, para empezar, son hombres que aman igualmente a los perros. Al inicio de la novela, el líder ruso aparece siempre en compañía de su perra Maya y luego, en Coyoacán, volverá a estar rodeado de perros y conejos. Algunos han atribuido a Trotski la frase "mientras más conozco a los hombres, más amo a mi perro", otros a Hitler y los más a Lord Byron. Pero en la novela de Padura la máxima hubiera sido suscrita por cualquiera de los dos personajes, que se unen, además, en una misma resolución ideológica, no carente de cierto escepticismo antropológico. Ambos, Trotski y Mercader, son, en la versión de Padura, soldados de una causa y sujetos dubitativos.

Claro que el retrato de Mercader es más sombrío que el de Trotski, pero el hijo de Caridad no carece de ciertas virtudes. Como su madre, es un enemigo del orden burgués y es dado a una bohemia radical, que toca fronteras con el vanguardismo (Padura 50). Mercader es, además, un romántico, ama a la Unión Soviética y a Stalin, pero también a sus mujeres, África y Sylvia -especialmente en los momentos en que se autorecrimina su "incapacidad de amar"- y a sus galgos rusos (482). Cuando Mercader le dice a África que es "un soldado y que va a donde lo manden" está inscribiendo su lealtad en una capacidad de amor que se transfiere a diversos sujetos, su madre, sus mujeres, sus ideas, sus galgos (124-25). Es un agente de la NKVD pero no es un autómata: está realmente convencido de que Andreu Nin y León Trotski son traidores, que hacen daño a la causa del comunismo mundial.

En los pasajes en que Ramón Mercader, haciéndose pasar por Jaime López, narra su historia al joven periodista cubano, en 1977, en La Habana, leemos la más clara legitimación del asesino de Trotski (181-91 y 237-48). Dado que López cuenta la biografía de Mercader desde el ardid de que el stalinista español ha muerto, la historia del homicida es referida por un nuevo Mercader, que ha renacido tras purgar veinte años de cárcel en Lecumberri y un regreso desolador al "deshielo" de Nikita Kruschev en la URSS, donde sus servicios a la patria de Lenin no son altamente valorados. Ese nuevo Mercader puede reconstruir con objetividad su pasado y concluir que "era un hombre de otra época, de un tiempo muy jodido, cuando no estaba permitida ni siquiera la duda" (243). Según el propio Mercader, para comprender su crimen atroz, "había que situarse en su mundo y en su tiempo" (243).

$111 \frac{\text { Revista Iberoamericana, Vol. LXXXV, Núm. 269, Octubre-Diciembre 2019, }}{1257-1270}$ 
Pero no eran aquellas las frases de un sujeto que siente compasión por sí mismo o arrepentimiento, sino de alguien que mira al pasado con la objetividad del materialismo histórico, que aprendió en sus lecturas de Bujarin y Stalin. Aunque hace decir a Mercader que en tiempos del stalinismo no había espacio para la duda, Padura sí presenta al asesino de Trotski como un comunista que también vacila y cuestiona. Por ejemplo, en un pasaje en el que se recrean los debates de fines de los 30, sobre la posición de la Unión Soviética ante las invasiones nazis de Austria y Checoslovaquia, el Pacto de Munich y el tratado Molotov-Ribbentrop, Mercader no coincide plenamente con su madre, Caridad, que justifica el "repliegue" de Stalin (285). Padura trata de mediar ideológicamente la ambivalencia por medio del discurso de Iván, pero la ambivalencia regresa cada vez que los actos de Mercader se describen como atributos del sujeto stalinista:

Aquélla era la crónica misma del envilecimiento de un sueño y el testimonio de uno de los crímenes más abyectos que se hubiera cometido, porque no solo atañía al destino de Trotski, al fin y al cabo contendiente de aquel juego por el poder y protagonista de varios horrores históricos, sino del de muchos millones de personas arrastradas -sin ellas pedirlo, muchas veces sin que nadie les preguntara jamás sus deseos- por la resaca de la historia y por la furia de sus patrones - disfrazados de benefactores, de mesías, de elegidos, de hijos de la necesidad histórica y de la dialéctica insoslayable de la lucha de clases. (320)

El ethos ambivalente de la era pos-soviética se afirma en el propio perfil de Trotski, que no siempre es favorable ni tampoco aprovecha plenamente los vastos recursos intelectuales del líder bolchevique. Padura se refiere muy superficialmente al ángulo letrado de Trotski, a su conocimiento exhaustivo de la filosofía occidental, no únicamente de la marxista, y sus pertinaces lecturas de historia, arte y literatura. El Trotski animal de lectura y erudito de bibliotecas y archivos, que lo hizo tan atractivo para grandes escritores y artistas del siglo XX, como André Gide o André Breton, George Orwell y Diego Rivera, no está plenamente dibujado. Tampoco el Trotski escritor prolífico, que, según la novela de Padura, pareciera haber sido sólo el autor de la Historia de la revolución rusa, en dos volúmenes, que varias veces se cita como Historia de la revolución, y del ensayo La revolución traicionada.

No sólo eso, tampoco la gran red epistolar que Trotski tejió desde México, con sus seguidores franceses, británicos, españoles, norteamericanos y latinoamericanos, como parte de la vertebración de la IV Internacional, está bien recreada en El hombre que amaba los perros. Biógrafos de Trotski, como Jean-Jacques Marie, dan a ese rebasamiento de fronteras la mayor importancia, en términos del sentido transnacional que siempre poseyó el trotskismo en Occidente (543-62). Ni siquiera la experiencia mexicana de Trotski, reconstruida exhaustivamente por Olivia Gall, alcanza en la 
novela de Padura una inscripción que rebase los lugares comunes de la relación con Frida y Diego, las visitas de Breton y Dewey, los ataques de Lombardo Toledano y David Alfaro Siqueiros y la hospitalidad de Lázaro Cárdenas (Gall 223-87).

Pero la mayor plasmación de una política de la memoria, desde la condición possoviética, que proyecta una moral de la ambigüedad con respecto a Trotski es que, como en el pasaje antes citado, el líder bolchevique se presenta varias veces como creador del mismo sistema que lo está devorando, por órdenes de Stalin. Esa perspectiva no sólo es ajena a las propias ideas de Trotski sino al contexto de la glasnost y la perestroika y a la caída del Muro de Berlín, en el 89, cuando la reivindicación de las víctimas de Stalin, especialmente aquellas inscritas en el campo intelectual (Pasternak, Esenin, Mandelstam, Ajmátova, el constructivismo ruso, Shostakóvich, Prokofiev) entendía al primer bolchevismo como damnificado y no como cómplice del stalinismo. La indistinción entre bolchevismo y stalinismo o entre Lenin y Stalin, en tanto creadores del mismo sistema, es más propia de visiones liberales de los 90, como la de Francois Furet en El pasado de una ilusión (1995) (Furet 171-73).

La filosofía neomarxista y la historiografía más reciente sobre la URRS, sin embargo, han comenzado a darle la razón nuevamente a Trotski, en el sentido de que había mayores diferencias entre el proyecto socialista bolchevique y el modelo stalinista de Estado, definitivamente edificado en 1936 y reproducido en Cuba cuarenta años después. Moshe Lewin, por ejemplo, ha hablado de una pugna entre "autonomización y federación" hasta 1924, en la que los soviets eran más hegemónicos que el partido y que inclinaba el sistema soviético hacia un tipo de Estado diferente al que Stalin construyó después (33-35). Otro historiador, Serhi Plokhy, ha sostenido la tesis de que las pautas de la Guerra Fría fueron creadas, en realidad, en la segunda mitad de los 30, cuando se institucionalizó plenamente el régimen soviético, bajo el modelo stalinista (25-27). La geopolítica del "socialismo en un solo país" era ajena al primer bolchevismo y a Trotski.

Al diseñar su novela, Leonardo Padura debió considerar, por lo menos, dos opciones: o colocarse plenamente en una perspectiva neotrotskista, que suscribiera la narrativa del propio Trotski sobre la revolución permanente, o acercarse a una postura liberal o socialdemócrata, que incluyera al trotskismo dentro de la "idea comunista del siglo XX", es decir, dentro del modelo de Estado stalinista que se construyó en la Unión Soviética, Europa del Este y Cuba. A mi juicio, el escritor se decantó por la segunda opción, lo cual le permitió una impugnación más clara del discurso oficial de la isla y, a la vez, un aprovechamiento de la neutralidad para restablecer, parejamente, el lugar del stalinismo y el trotskismo en la historia del siglo XX. Dado que en ningún momento de la novela se alude directamente a la adopción en la isla del mismo modelo stalinista que se critica, el texto se apropia hábilmente del tabú, de los silencios y de la política de lo indecible que caracteriza a la opacidad oficial.

$111 \frac{\text { Revista Iberoamericana, Vol. LXXXV, Núm. 269, Octubre-Diciembre 2019, }}{1257-1270}$ 
Zygmunt Bauman caracteriza la última modernidad como un periodo en que el ethos de la ambivalencia se difumina entre los discursos y las prácticas culturales. La ambivalencia, dice Bauman, responde a la necesidad de ordenamiento del caos posmoderno y de pluralización de políticas de la memoria (19-39). A propósito del holocausto, advierte que esa moral de la ambigüedad puede producir representaciones escandalosas, por su ingravidez o su forzada imparcialidad (42-50). La novela de Leonardo Padura ofrece una modalidad parecida de documento, que logra decir sin decir o diciendo oblicuamente, reconstruyendo la historia del stalinismo, de sus crímenes contra Trotski, el primer bolchevismo y la oposición de izquierda, sin implicar directamente el capítulo cubano de esa trama, a pesar de que su leitmotiv sea la residencia de Ramón Mercader en La Habana.

El hombre que amaba los perros es una novela que ironiza, ejemplarmente, el mecanismo de la autocensura en la cultura cubana. Como en la Oda a Stalin de Osip Mandelstam, analizada por J. M. Coetzee -o en la Autocrítica de Heberto Padilla ante la UNEAC en 1971-, el texto expone abiertamente sus silencios, como si procediera por medio de una verbalización del interdicto (Padura 133-46). La pasión de silenciar se ha transferido del poder del Estado a la poética literaria del autor, por medio de una sofisticada ficcionalización de la historia. Pocas novelas trasmiten con tanta elocuencia los dilemas de la memoria y el olvido en la extraña condición pos-soviética cubana. Cuba es, aquí, un país en que el comunismo pasó y, a la vez, sigue presente. Nada más y nada menos que como en la propia realidad.

\section{BiBLIOGRAFÍA}

Armengol, Alejandro. "Padura, el Che y la atracción trotskista". Cubaencuentro. 13 ago. 2013. <http://www.cubaencuentro.com/cultura/articulos/padura-el-che-y-laatraccion-trotskista-296576>. 24 junio 2018.

Balibar, Étienne. Sobre la dictadura del proletariado. Madrid: Siglo XXI, 2015.

Bauman, Zygmunt. Modernidad y ambivalencia. Madrid: Anthropos, 2005.

Cabrera Infante, Guillermo. Mea Cuba, antes y después. Barcelona: Galaxia Gutenberg, 2015.

Casamayor-Cisneros, Odette. Utopía, distopía e ingravidez: reconfiguraciones cosmológicas en la narrativa postsoviética cubana. Madrid/Frankfurt: Editorial Iberoamericana/Vervuert, 2013.

Coetzee, J.M. Contra la censura. Ensayos sobre la pasión de silenciar. Barcelona: Debate, 2007.

Cuesta, LeonelAntonio de la. Constituciones cubanas. Miami:Alexandria Library, 2007. Cuesta, Mabel. Cuba postsoviética: un cuerpo narrado en clave de mujer. Santiago de Chile: Cuarto Propio, 2013.

$111 \frac{\text { Revista Iberoamericana, Vol. LXXXV, Núm. 269, Octubre-Diciembre 2019, } 1257-1270}{\text { ISSN 2154-4794 (Electrónico) }}$ 
Dean, Jodi. "Deseo comunista". La idea del comunismo. The New York Conference (2011). Slavoj Žižek, ed. Madrid: Akal, 2014. 99-115.

Dilla, Haroldo. "De utopías, revoluciones y escombros". Este País 285 (2015): 5-8.

Farber, Samuel. "La izquierda y la transición cubana. En diálogo con El hombre que amaba los perros de Leonardo Padura". Nueva Sociedad 238 (2012): s/p.

Ferrari, Guillermina de. Community and Culture in Post-soviet Cuba. Nueva York: Routledge, 2014.

Franqui, Carlos. Retrato de familia con Fidel. Barcelona: Seix Barral, 1981.

Furet, Francois. El pasado de una ilusión. Ensayo sobre la idea comunista en el siglo XX. México D.F.: FCE, 1995.

Gall, Olivia. Trotsky en México y la vida política en el periodo de Cárdenas, 19371940. México D.F.: Era, 1991.

Iber, Patrick. Neither Peace nor Freedom. The Cultural Cold War in Latin America. Cambridge: Harvard UP, 2015.

Kagarlitsky, Boris. Los intelectuales y el Estado soviético. De 1917 a nuestros días. Buenos Aires: Prometeo, 2005.

Koestler, Arthur. El mito soviético ante la realidad. México D.F.: Ediciones Estela, 1946.

Lewin, Moshe. El siglo soviético. ¿Qué sucedió realmente en la Unión Soviética? Barcelona: Crítica, 2005.

Loss, Jacqueline. Dreaming in Russian: The Cuban Soviet Imaginary. Austin: U of Texas P, 2013.

y José Manuel Prieto, eds. Caviar with Rum. Cuba-USSR and the Postsoviet Condition. Nueva York: Palgrave McMillan, 2012.

Luis, William. Lunes de Revolución. Literatura y cultura en los primeros años de la Revolución cubana. Madrid: Verbum, 2003.

Marie, Jean-Jacques. Trotski. Revolucionario sin fronteras. México D.F.: FCE, 2009. Martínez Heredia, Fernando. La crítica en tiempo de Revolución. Antología de Pensamiento Crítico. Santiago de Cuba: Editorial Oriente, 2010.

Méndez Moissen, Sergio. “El trotskismo cubano en la Revolución de 1933”. Pacarina del Sur. 6 marzo 2015. <http://www.pacarinadelsur.com/home/abordajes-ycontiendas/1126-el-trotskismo-cubano-en-la-revolucion-de-1933>. 24 junio 2018.

Montenegro, Nivia y Enrico Mario Santí, ed. Infantería. México D.F.: FCE, 1999.

Padura, Leonardo. El hombre que amaba los perros. Barcelona: Tusquets, 2009.

Plokhy, Serhi. El último imperio. Los días finales de la Unión Soviética. Madrid: Turner, 2014.

Puñales-Alpízar, Damaris. Escrito en cirílico: el ideal soviético en la cultura cubana postnoventa. Santiago de Chile: Cuarto Propio, 2013.

Roca, Blas. Los fundamentos del socialismo en Cuba. La Habana: Ediciones Populares, 1960.

$111 \frac{\text { Revista Iberoamericana, Vol. LXXXV, Núm. 269, Octubre-Diciembre 2019, }}{1257-1270}$ 
Rojas, Rafael. "Nahuel Moreno y la crítica trotskista al socialismo cubano". 30 oct. 2011. <www.librosdelcrepusculo.net/2011/10/nahuel-moreno-y-la-criticatrotskista.html>. 24 junio 2018.

Ruda, Frank. "Recordar lo imposible: para una anamnesis metacrítica del comunismo". La idea del comunismo. Slavoj Žižek. Madrid: Akal, 2014. 177-218.

Stalin, J. V. Constitución de la URSS. México D.F.: Editorial Dialéctica, 1937.

Stonor Saunders, Frances. La CIA y la Guerra Fría cultural. Barcelona: Debate, 2001.

Toussaint, Eric. "Revolucionarios 'olvidados' de la historia”. Rebelión. 25 julio 2013. $<$ http://www.rebelion.org/noticia.php?id=171671>. 24 junio 2018.

Trotski, León. Escritos latinoamericanos. En México (1937-1940). México D.F.: Casa León Trotski, 2013.

La revolución traicionada. México D.F.: Museo Casa de León Trotski, 2014. Stalin. 2010. <https://www.marxists.org/espanol/trotsky/1940s/stalin/13_sup1. htm>. 24 junio 2018.

Žižek, Slavoj, ed. La idea del comunismo. The New York Conference (2011). Madrid: Akal, 2014.

Palabras clave: Leonardo Padura - El hombre que amaba a los perros - (auto) censura - stalinismo cubano - trotskismo cubano

Recibido: $\quad$ agosto 2016

Aceptado: $\quad$ mayo 2017 